\title{
Research Advance on Draw Solution in Forward Osmosis Process
}

\author{
Boyu Liư ${ }^{a}$, Jiang Yu, Donglang Li, Dan Lv, Juan Zhang \\ Engineering College , Jiangsu Xuzhou , 221004 \\ aescalater@126.com
}

\begin{abstract}
Keywords: Osmosis draw solution research
Abstract:Forward osmosis (FO) process is a new membrane separation process that developed in recent years; it is driven by the osmosis pressure difference of solution on both sides of membrane. Forward osmosis process don't need to force energy-driven extra, and the main energy consumption of the whole craft focuses on draw solution regeneration process, therefore, draw solution process relates directly to the running cost of the whole forward system.
\end{abstract}

\section{Introduction}

Draw solution in forward osmosis process is the origin of driving force and the core part of forward osmosis process. The choice of draw solution should follow these following principles: firstly, it must have high enough osmosis pressure to insure higher osmosis driving force; secondly, draw solution should be easy to recycle by concentrating and reseparating so that to insure acquiring pure water and reutilization; thirdly, it should be nontoxic, cheap, stable, and it would not destroy membrane by chemical means like dissolution and physical means like pollution. Forward osmosis is a kind of very potential technology which is friendly to environment, and it is promising in the field of seawater desalting[1], sewage purification[2], food, medicine, energy and so on[3-4].

\section{Draw Solution Characteristics Impact on the Craft of Forward Osmosis}

As analyzing from draw solution character, the key that draw solution impacts on forward osmosis is the choice of solute, and solute character mainly expresses on following aspects: solute solubility, solution viscosity, solute molecular mass and solute reverse osmosis.

\section{Solute Solubility of Draw Solution Solute}

The higher solute solubility in water, the higher obtained draw solution concentration, the higher generated osmosis pressure, the higher water flux, and the faster regeneration rate. But the growth is non-linear, and exorbitant draw solution concentration may bring adverse effects, like enlarging solution viscosity, intensifying concentration polarization.

\section{Draw Solution Viscosity}

Solute character determines draw solution viscosity directly. The lower draw solution viscosity, the higher speed that molecular spreads in draw solution, the higher exchange speed on both sides of membrane, the lower concentration polarization degree, and the higher water flux.

\section{Solute Molecular Mass of Draw solution solute and Solute Reverse Osmosis}

Fasten the mass concentration draw solution, the lower solute molecular mass, the more particle that draw solution includes, the higher generated osmosis pressure, and the higher water flux; but the too low solute molecular mass may lead to that reverse osmosis magnifies. If draw solution solute permeate reversely to raw material solution, on the one hand, it may vastly reduce the osmosis pressure on both sides of membrane, decrease the driving force of osmosis process, and lead to the decline of raw material solution separation rate; on the other hand, solute permeate reversely may bring new impurity in raw material solution and may have an effect on the follow-up processing of raw material solution. 
Through the above analysis, the ideal draw solution should have these characteristics: solute solubility in water is high, solute molecular mass is small enough, viscosity is low, solute reverse osmosis is little.

\section{The Research and Application of Draw Solution}

The research of draw solution has started as early as 1960s, in recent more than ten years, the kind and regeneration means both have obtained considerable development. As analyzing from the kind of draw solution solute, draw solution solute which is researched and reported at present can be mainly divided into volatile gas, inorganic salt solute, organic solute and synthetic material solute. This thesis divides it into 2 kinds on the basis of whether to recycle existing draw solution to make a brief discussion.

\section{Direct Use Type}

Glucose solution is the representative of direct use type draw solution. The forward osmosis water filter which developed by HT1 company adopts edible draw solution (saccharides or beverage powder). When immersing water filter into wave (like brine, sewage), water will penetrate forward osmosis membrane into draw solution, and the diluted draw solution can be supplied for human to drink. The dilute draw solution is rich in nutriment and mineral element, and the pollutant in wave (like suspended solid, organics) is held back. Now this kind of product is only used in the field of military, expedition, disaster assistance. Its applied range is narrow, and its applicable scale is small, it doesn't suit for large-scale water treatment project.

\section{Recycling Type \\ Volatile Gas}

When volatile gas dissolved in the water, it can form high osmotic pressure and the gas can be recycled when heated. That is an ideal option to be an draw solution. To be an draw solution, it requires the volatile gas to be high solubility in water, and it is usually a high dissolved gas with acidic or alkaline such as $\mathrm{SO}_{2}$ or $\mathrm{NH}_{3}$.

In an experiment, Batchelder [5] take $\mathrm{SO}_{2}$ as draw solution and he recycled it with the heating method and air striping method. On this basis, to improve the penetration effect, McGinnis [6] take $\mathrm{KNO}_{3}$ and $\mathrm{SO}_{2}$ as draw solution to be used for the second grade $\mathrm{FO}$ seawater desalination technology. $\mathrm{KNO}_{3}$ was to be used for the first FO draw solution. Because the $\mathrm{KNO}_{3}$ solubility is highly dependent on temperature, the precipitate can be regenerated by cooling and crystallization. $\mathrm{SO}_{2}$ is used for the second FO draw solution, which was recycled by heating or air striping method.

In the group of Elim-elech[7], they prepared more than 25MPa high osmotic pressure draw solution which was made by a certain mix of $\mathrm{NH}_{3}$ and $\mathrm{CO}_{2}$ dissolved in water and it greatly enhanced water flow. The $\mathrm{NH}_{3}$ and $\mathrm{CO}_{2}$ in draw solution can be recycled when it was heated up to $60^{\circ} \mathrm{C}$. In general, the draw solution which is made by volatile gas has high osmotic pressure and more flow. But because of the high cost when heating and the $\mathrm{SO}_{2}, \mathrm{NH}_{3}$ are active gas which may not save when operating, as Fig.1. 
forward osmosis membrane

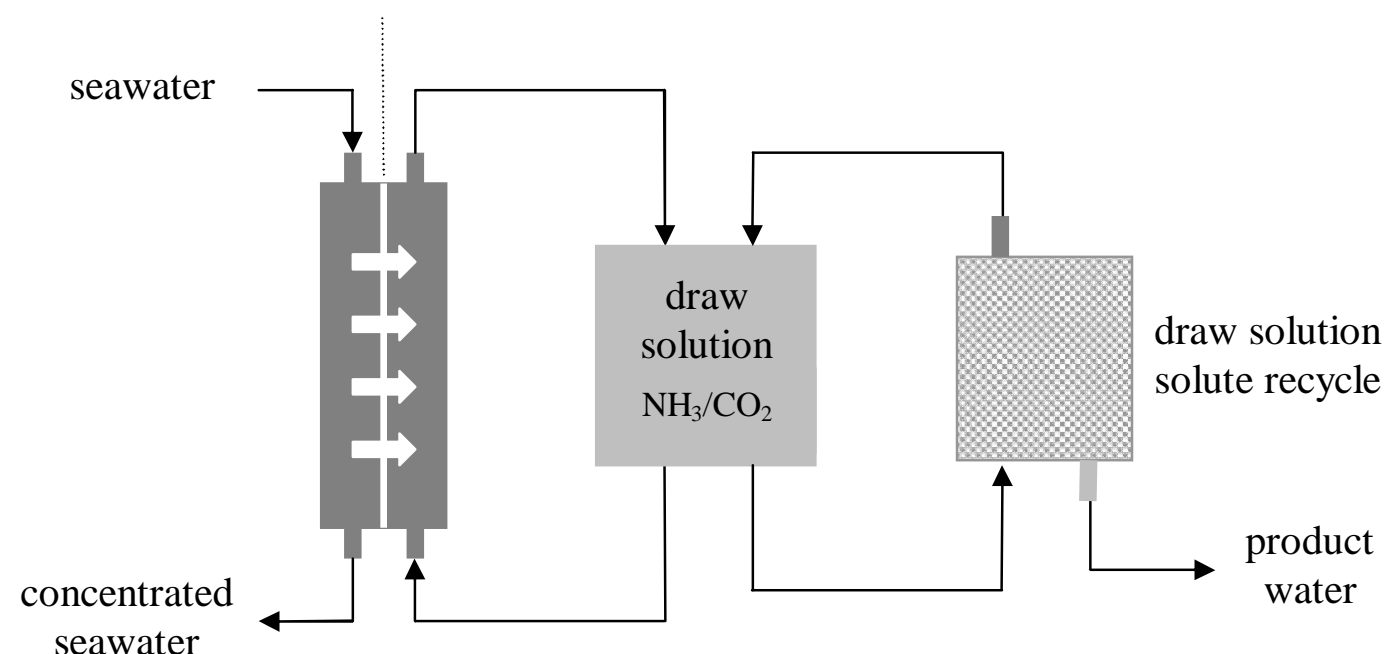

Fig.1 $\mathrm{NH}_{3} / \mathrm{CO}_{2}$ forward osmosis system

\section{Magnetic Draw Solution}

Magnetic CNPs (MNPs) consists of magnetic cores and hydrophilic polymer shell. It has good hydrophilicity, small particle size. Not only does it can produce high osmotic pressure and water flow but also can operate the separation by magnetic field or low pressure.

The group from Singapore researched on the surface of magnetic CNPs and they changed the hydrophilic functional groups on it for forward osmosis experiment. The experimental results showed that the CNPs draw solution which surface was modified with PAA polyacrylic acid can provide a higher driving force and high water flow. After, the group modified CNPs draw solution with Polyethylene glycol (peg) dicarboxylic acid on the surface. By adjusting the Ferric acetylacetonate and polyethylene glycol (peg) dicarboxylic acid ratio, they get particle size distribution between $4.2 \sim 17.5$ $\mathrm{nm}$ magnetic nano-particles. The pure water flow can be up to $10 \mathrm{~L} /\left(\mathrm{m}^{2} \cdot \mathrm{h}\right)$ with DI water as raw materials. During this new type of magnetic draw solution providing high penetration, fresh water can be easily separated by magnetic device to realize recycling. But with the increasing the number of recycled and used, the draw solution magnetic particles get together which affect the draw solution osmotic pressure and reduce the water flow. In addition because of the draw solution will cost a lot when prepared in the laboratory and the potential use of limited, so it needs to be further researched.

\section{Inorganic Salt Solute}

Inorganic usually has low molecular mass and high solubility of the inorganic salt can produce higher osmotic pressure and it is very cheap when become commoditized. So it is easier to be studied and that is why inorganic salt solution is one of the most commonly used draw solution in penetrating draw solution research.

In order to overcome the small molecule inorganic salt reverse diffusion serious shortcomings, more researches were studied on greater nuclear inorganic salt which is divalent trivalent or higher. Tan[8] find out that at the same concentration degree and operating conditions, $\mathrm{MgSO}_{4}$ and $\mathrm{Na}_{2} \mathrm{SO}_{4}$ reverse osmotic quantity were lower than that of $\mathrm{NaCl}$ and $\mathrm{KCl}$. And the $\mathrm{MgSO}_{4}$ intercept rate has reached 99.99\%. In the research of Phuntsho[9], $\mathrm{KCl}, \mathrm{NaNO}_{3}$ and $\mathrm{KNO}_{3}$ have highest water flow while $\mathrm{NH}_{4} \mathrm{H}_{2} \mathrm{PO}_{4},\left(\mathrm{NH}_{4}\right)_{2} \mathrm{HPO}_{4}, \mathrm{Ca}\left(\mathrm{NO}_{3}\right)_{2}$ and $\left(\mathrm{NH}_{4}\right)_{2} \mathrm{SO}_{4}$ have low reverse osmotic when dissolved. The group of $\mathrm{Liu}[10]$ took $\mathrm{Al}_{2}\left(\mathrm{SO}_{4}\right)_{3}$ as draw solution, they found that there is no reverse diffusion when $\mathrm{Al}^{3+}$ in the forward osmosis process and permeable membrane have intercept rate as high as $99.99 \%$ for $\mathrm{Al}^{3+}$. In conclusion, it has the advantage of big osmotic pressure and high water flow, but it has solute reverse osmosis. In contrast, charged ions has less solute reverse osmosis compared with low state of inorganic salt and more appropriate to technological requirements. 


\section{Organic solute}

Compared with inorganic salt, water solute organic matter molecular mass is bigger, so is not easy to reverse osmosis, also is chosen for draw solution. Currently organic matter which is used in the study of leaking of is mainly sugar material, 2-methyl imidazoles compounds, polyelectrolyte.

T.S.Chung team published the research result about draw solution of forward osmosis whose solute is compounded as 2-methyl imidazoles. Colligative properties by solution to estimate the draw solution osmotic pressure of up to $35 \mathrm{MPa}$. In addition, the experiment also uses the membrane distillation recycling draw solution under $70{ }^{\circ} \mathrm{C}$. Recycling is realized. And apply for the related patent ( US0224476 ) .

\section{Intelligent gels}

Ion polymer hydrogels is three-dimensional network structure, and its hydrophilic group can swell, in environmental stimuli (pressure, heating, pressure + heat) it can release water again, this expansion expansion is a reversible change of volume, the release rate is faster in double stimulation of water pressure and heat. Li prepared 4 kinds of hydrogel, the ionic polyacrylic acid sodium (PSA), acrylic acid and N '- isopropyl acrylamide copolymer (PSA - NIPAM) and nonionic polyacrylamide (PAM) and poly ( $\mathrm{N}$ - isopropyl acrylamide) (PNIPAM). Considering water flux and water recovery, PSA NIPAM optimal is performance, with liquid mass fraction $0.2 \% \mathrm{NaCl}$ solution as raw material, the initial water flux is $0.71 \mathrm{~L} / \mathrm{h} .\left(\mathrm{m}^{2} \cdot \mathrm{h}\right)$. Due to the gel are macromolecules, the water flux is low, will largely limit the application of the law. Zeng blend reduction of graphene oxide (rGO) into gel. A small amount of rGO can increase the softness of composite hydrogel and the performance between particles, particles - membrane contact, when in $0.2 \% \mathrm{NaCl}$ solution is raw material to liquid, inclusive of our $1.2 \%$ mass fraction of rGO polyacrylic acid sodium solution is draw solution, water flux is as high as $8.2 \mathrm{~L} /\left(\mathrm{m}^{2} \cdot \mathrm{h}\right)$. Moreover, that with a light absorption of $\mathrm{rGO}$ through absorbing rise temperature of solution, and then improving the efficiency of gel dehydration, reducing energy consumption of regeneration, is a promising method.

\section{Conclusion}

To sum up, with the potential advantages and application value of is penetrating technology gradually is attented, the research of forward osmosis technology also will increase increasingly. High efficient absorption of the fluid development and regeneration process optimization will become a key breakthrough of forward osmosis technology's development and application. In the study of draw solution of forward osmosis, although it has developed many kind of draw solution, and is also carried out related research about the performance of draw solution, but these studies are limited in laboratory, and as to the performance of draw solution was evaluated by water flux and the reverse osmolality of solution. As the forward osmosis technology is moving towards practical application from laboratory, draw solution's stability and operational in infiltration system with large-scale, long period in the process of running will be the important factors in the future study. Therefore that increasing draw solution osmotic pressure and the water flux in forward osmosis process, and developing more energy efficient regeneration technology will also be an important direction of research in the future.

\section{References}

[1]MCGINNIS R L, ELIMELECH M. GlobM Challengesin Energy and Water Supply: the Promise of Engineered Osmosis[J], Envi-ion. SOi. Techn01. 2008, 42(23): 8625-8629.

[2]MCCUTCHEONJ R, MCGINNISRL, ELIMELECHM. A Novel Ammonia-Carbon Dioxide Forward(Direct)Osmosis Desalina-tionProcess[J]. Desalination, 2005, 174(1): 1—11.

[3]MCCUTCHEONJ R, MCGINNISRL, ELIMELECHM. Desali-nation by Ammonia. Carbon DioxideForward Osmosis: Influence of Draw and Feed Solution Concentrations on Process Performance[J]. J. Membr. Sci. , 2006, 278(1-2): 114-123. 
[4] Yu Qianhong Chi lina, Zhou Weili, etc. permeable membrane separation technology and its application in water treatment and research [J]. Journal of environmental science and technology, 2010 33(3) : $117-122$.

[5]BatchelderGW. Process for the demine ralization of water:US,3171799[P].1965 - 03 - 02.

[6]McGinnisRL. Osmotic method for extraction of solvent from a solution involves subjectting solution to forward osmosis, and manipulating thermal and osmolar conditions of solution sin series of reactions:US, 6391205 - B1[P].2002 - 05 - 21.

[7]McGinnisRL, ElimelechM. Energy require ments of ammonia-car-bondioxide forward osmosis desalination[J]. Desalination, 2007, 207(1/2/3):370 - 382.

[8]TanCH, NgHY. Anovelhy brid forward osmosis nano filtration (FO-NF)process for seawater desalination:Draw solution selection and system configuration [J]. Desalin Water Treat, 2010,13(1/2/3):356 - 361 .

[9]PhuntshoS, ShonHK, HongS, etal. A novel lowenergy fertilizer driven forward osmosis desalination for direct fertigation:Evaluating the performance of fertilizer draw solutions[J] . JMembrSci, 2011, 375(1/2): 172 - 181 .

[10]LiuZY, BaiHW, LeeJ, etal. Alow-energy forward osmosis process to produce drinking water[J]. EnergEnvironSci, 2011, 4(7): 2582 - 2585. 